\title{
Rainbows should reign not only on LGBTQ+ STEM Day
}

\author{
The international day of LGBTQ+ people in STEM, 18 November, celebrates diversity in sexuality and gender \\ identity, and raises awareness of persisting obstacles and challenges for LGBTQ+ scientists. It is important that \\ the scientific community, journals and publishers included, creates the conditions that allow LGBTQ+ scientists to \\ thrive - not only today, but every day.
}

S ixty years ago on this day, the American astronomer Frank Kameny fought in the US Supreme Court to appeal a decision to fire him because of his sexuality. Kameny, who was expelled from his position as astronomer for the Army Map Service after he refused to answer questions about his sexuality, later became a full-time activist. During his lifetime he actively promoted the rights of gay people and fought for the removal of the classification of homosexuality as a mental disorder from the American Psychiatric Association's Diagnostic and Statistical Manual of Mental Disorders ${ }^{1}$.

Drawing attention to the persisting challenges and in honour of Kameny's activism, international LGBTQ+ STEM Day - 18 November - promotes inclusivity in STEM fields, celebrating all gender identities and sexual orientations.

Despite the passing of more liberal laws over recent decades, at least in some countries, scientists who identify as LGBTQ+ are still facing challenges to a disproportionate degree. For example, it has only been just over a year since the US Supreme Court officially ruled that the Civil Rights Act of 1964 also protects the rights of gay, bisexual and transgender workers ${ }^{2}$.

For LGBTQ+ scientists, the decision of whether to be 'out' is often influenced by various considerations related to discrimination and bias in the workplace. Statistics suggest that, in STEM, as many as 40 per cent of LGBTQ+ scientists are not out to their colleagues ${ }^{3}$. A hostile institutional atmosphere or prevailing heteronormativity (that is, the assumption of hetereosexuality as being predominant, ideal and privileged) make being open about one's gender identity or sexuality difficult and potentially risky ${ }^{4,5}$. In addition, some scientists are afraid that being openly gay, transgender or queer will be disadvantageous to their career, a worry that has been documented in research ${ }^{6}$.

Research also shows that LGBTQ+ scientists are significantly more likely to experience mental and physical problems and to consider leaving academia ${ }^{7}$. In a

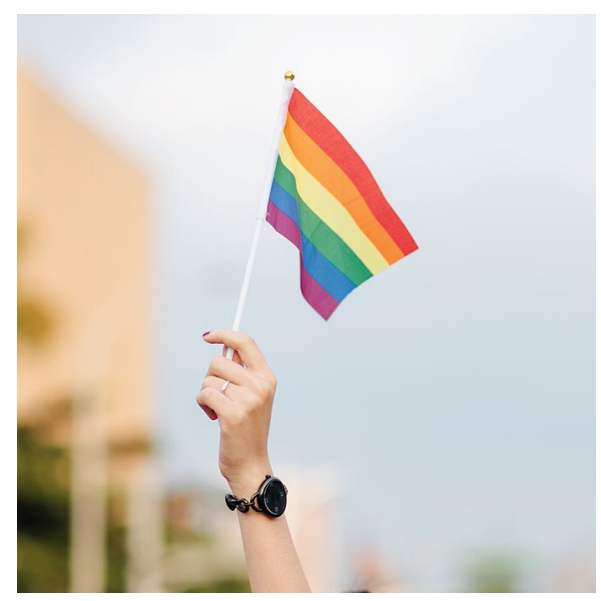

Credit: Watsamon Tri-Yasakda / EyeEm / Getty

survey conducted by the Institute of Physics, the Royal Astronomical Society and the Royal Society of Chemistry in 2019, 28\% of the respondents stated they have considered leaving their workplace because of a climate of discrimination against LGBTQ+ people ${ }^{8}$. Sixteen per cent of the respondents even reported having personally experienced harassment or other exclusionary behaviour.

The current issue of Nature Human Behaviour features two opinion pieces in which scientists and members of the LGBTQ+ community share their personal experiences, highlighting barriers in academia and offering calls to action. Ruth Pearce ${ }^{9}$ reminds us that academic institutions still have a long way to go to become truly inclusive. As she explains, proponents of academic freedom have long defended it as a means to pursue knowledge uncensored by state or religious authorities. However, she posits that freedom of speech and academic freedom are increasingly being abused to attack the LGBTQ+ community and their allies. Pearce raises concerns about how this affects minority groups and their ability to speak out about discrimination and against harassment.

Christina Atchison ${ }^{10}$ shares her experience of doing scientific fieldwork as a member of the LGBTQ+ community. She describes how not being able to disclose her identity when doing fieldwork in a country or culture where being out is illegal or unsafe not only affected her well-being but also her career choices. She urges STEM institutions to be alert about such safety issues associated with fieldwork for LGBTQ+ scientists and to include them in standard travel risk assessments.

Increasing visibility and representation is important. Campaigns such as 500 Queer Scientists (https://500queerscientists. $\mathrm{com} /$ ) promote awareness, visibility and recognition of LGBTQ+ scientists. Nevertheless, while raising awareness is a crucial first step, it is not sufficient in itself. Rather, scientific institutions and individuals need to take an active role in creating communities in which LGBTQ+ scientists can thrive.

While many institutions have diversity, inclusion and equity policies in place, continued efforts are necessary to ensure that these policies are adhered to in practice. Importantly, institutions need to be alert to the possibility that certain policies, although well-intended, can fail to achieve their aim and can in fact be detrimental to individuals ${ }^{11}$. To make sure that policies do not overlook the needs of marginalized groups and to avoid harm, community representatives need to be included in diversity and recruitment committees.

Journals (and publishers) also have an important role. We must strive to be representative of and reach the scientific community at large, using our platforms as instruments for increasing diversity and amplifying the voices of LGBTQ+ scientists. It is paramount that we enable open discussions of discrimination and exclusion, as we continue to face uncomfortable truths and continuously ask ourselves where our blind spots are, and how we can change.

Scientific research benefits tremendously from diverse viewpoints and input. Failing to create a safe, inclusive atmosphere in which LGBTQ+ scientists can thrive puts academia at risk of losing 
many bright, talented scientists and remaining an exclusionary heteronormative community.

It is our shared responsibility to nurture a diverse scientific landscape and research communities and to celebrate diversity rather than stifle it. LGBTQ+ STEM Day serves as an important reminder for this: increasing diversity and inclusion in academia should be our priority every day.
Published online: 18 November 2021

https://doi.org/10.1038/s41562-021-01239-w

References

1. Crain, C. Frank Kameny's orderly, square gay-rights activism. New Yorker, https://go.nature.com/3BnqBwG (22 June 2020).

2. Liptak, A. Civil Rights Law Protects Gay and Transgender Workers, Supreme Court Rules. NY Times, https://go.nature. com/3nE0blj (15 June 2020)

3. Yoder, J. B. \& Mattheis, A. J. Homosex. 63, 1-27 (2016).

4. Marín-Spiotta, E. et al. Adv. Geosci. 53, 117-127 (2020).
5. Barres, B., Montague-Hellen, B. \& Yoder, J. Genome Biol. 18, 62 (2017).

6. Cech, E. A. \& Pham, M. V. Soc. Sci. 6, 12 (2017).

7. Cech, E. A. \& Waidzunas, T. J. Sci. Adv. 7, eabe0933 (2021).

8. Institute of Physics, Royal Astronomical Society \& Royal Society of Chemistry. Exploring the Workplace for LGBT+ Physical Scientists, https://www.rsc.org/globalassets/04-campaigning-outreach/ campaigning/lgbt-report/lgbt-report_web.pdf (2019).

9. Pearce, R. Nat. Hum. Behav. 11, https://doi.org/10.1038/s41562021-01214-5 (2021)

10. Atchison, C. Nat. Hum. Behav. 11, https://doi.org/10.1038/ s41562-021-01205-6 (2021).

11. Galinsky, A. D. et al. Perspect. Psychol. Sci. 10, 742-748 (2015). 